\title{
Vascular Calcification
}

National Cancer Institute

\section{Source}

National Cancer Institute. Vascular Calcification. NCI Thesaurus. Code C114846.

Deposition of calcium in vascular structures. 